\title{
Cytokine Signaling Through the Novel Tyrosine Kinase RAFTK in Kaposi's Sarcoma Cells
}

\author{
Zhong-Ying Liu, ${ }^{\star}$ Ramesh K. Ganju, ${ }^{\star}$ Jian-Feng Wang, ${ }^{*}$ Mel A. Ona, ${ }^{\star}$ William C. Hatch, ${ }^{*}$ Tong Zheng, ${ }^{\ddagger}$ Shalom Avraham, \\ Parkash Gill, ${ }^{\ddagger}$ and Jerome E. Groopman* \\ *Divisions of Experimental Medicine and Hematology/Oncology, Beth Israel Deaconess Medical Center, Harvard Medical School, \\ Boston, Massachusetts 02215; and ${ }^{\ddagger}$ Division of Hematology/Oncology, Norris Cancer Center, University of Southern California, \\ Los Angeles, California 90033
}

\begin{abstract}
A number of cytokines, including basic fibroblast growth factor (bFGF), vascular endothelial growth factor (VEGF), oncostatin M (OSM), IL-6, and tumor necrosis factor alpha $(\mathrm{TNF}-\alpha)$, have been postulated to have a role in the pathogenesis of Kaposi's sarcoma (KS). The proliferative effects of bFGF and OSM may be via their reported activation of the c-Jun $\mathrm{NH}_{2}$-terminal kinase (JNK) signaling pathway in KS cells. We now report that KS cells express a recently identified focal adhesion kinase termed RAFTK which appears in other cell systems to coordinate surface signals between cytokine and integrin receptors and the cytoskeleton as well as act downstream to modulate JNK activation. We also report that the tyrosine kinase receptor FLT-4, present on normal lymphatic endothelium, is robustly expressed in KS cells. Treatment of KS cells with VEGF-related protein (VRP), the ligand for the FLT-4 receptor, as well as with the cytokines bFGF, OSM, IL-6, VEGF, or TNF- $\alpha$ resulted in phosphorylation and activation of RAFTK. Following its activation, there was an enhanced association of RAFTK with the cytoskeletal protein paxillin. This association was mediated by the hydrophobic $\mathrm{COOH}$-terminal domain of the kinase. Furthermore, JNK activity was increased in KS cells after VEGF or VRP stimulation. We postulate that in these tumor cells RAFTK may be activated by a diverse group of stimulatory cytokines and facilitate signal transduction to the cytoskeleton and downstream to the growth promoting JNK pathway. (J. Clin. Invest. 1997. 99:17981804.) Key words: RAFTK, related adhesion focal tyrosine kinase $\bullet$ Kaposi's sarcoma (KS) • cytokines
\end{abstract}

\section{Introduction}

Kaposi's sarcoma $(\mathrm{KS})^{1}$ is the most frequently observed neoplasm arising among patients with AIDS. The cell of origin is

The first two authors, Z.Y. Liu and R.K. Ganju contributed equally to this work.

Address correspondence to Dr. Jerome E. Groopman, Chief, Divisions of Experimental Medicine, Beth Israel Deaconess Medical Center (West Campus), Harvard Institutes of Medicine, One Deaconess Road, Boston, MA 02215. Phone: 617-667-0070; FAX: 617-975-5240; E-mail: jgroopma@west.bidmc.harvard.edu

Received for publication 25 October 1996 and accepted in revised form 10 January 1997.

J. Clin. Invest.

(C) The American Society for Clinical Investigation, Inc.

0021-9738/97/04/1798/07 \$2.00

Volume 99, Number 7, April 1997, 1798-1804 believed to be from the lymphatic endothelium (1-2). Etiological factors implicated in KS include the recently discovered human herpesvirus 8 (HHV-8)/Kaposi's sarcoma herpesvirus (KSHV) and TAT, the soluble transcriptional activator of HIV (3-7). Considerable data indicate a role for endogenous and exogenous cytokines in the pathogenesis of KS (8-16). Growth factors such as basic fibroblast growth factor (bFGF) and vascular endothelial growth factor (VEGF), which are known to stimulate the mitogenesis of certain types of endothelium, as well as Oncostatin M (OSM), IL-6, and tumor necrosis factor alpha (TNF- $\alpha$ ) which are elaborated during inflammatory conditions, have been implicated in promoting $\mathrm{KS}$ cell growth (17-25).

Defining the signal transduction pathways which may be utilized by cytokines that appear to modulate KS growth provides an opportunity for the rational and targeted therapeutic intervention against this neoplasm. One issue that is immediately apparent is that the cytokines described to date as promoting KS belong to distinctly different families as defined by their receptors. VEGF and bFGF receptors belong to the protein tyrosine kinase family, OSM and IL-6 utilize a common gp130 subunit, and TNF- $\alpha$ receptors are members of the Fas/ apoptosis CD95 family. Given this diversity, we have further characterized the downstream signaling pathways triggered by cytokine treatment in permanent human KS cells in vitro and sought a common molecule among these different pathways. We observed that KS cells express a newly identified signaling molecule termed related adhesion focal tyrosine kinase (RAFTK), also known as Pyk2 or CAK- $\beta$ (26-29). RAFTK is a member of the focal adhesion kinase (FAK) family and has considerable deduced amino acid and structural similarity with FAK. Previously, RAFTK has been reported to link calcium and integrin-mediated signaling to the cytoskeleton in brain and hematopoietic cells (26-29).

In KS cells, we find that treatment with cytokines from different families, including bFGF, OSM, IL-6, VEGF, and TNF- $\alpha$, all led to the phosphorylation and activation of RAFTK. After cytokine treatment, RAFTK was found to associate with the cytoskeletal protein paxillin. We have extended this observation and focused on the tyrosine kinase receptor termed FLT-4, which has been found in fetal and adult lymphatic endothelium (30-32). KS cells expressed the FLT-4 receptor, and treatment with its newly discovered ligand called VEGF-

1. Abbreviations used in this paper: bFGF, basic fibroblast growth factor; GST, glutathione $S$-transferase; JNK, c-Jun $\mathrm{NH}_{2}$-terminal kinase; KS, Kaposi's sarcoma; OSM, Oncostatin M; RAFTK, related adhesion focal tyrosine kinase; TNF- $\alpha$, tumor necrosis factor alpha; VEGF, vascular endothelial growth factor; VRP, VEGF-related protein. 
related protein (VRP) or VEGF-C (33-34), again resulted in the phosphorylation of RAFTK.

Recent studies have identified the c-Jun $\mathrm{NH}_{2}$-terminal kinase (JNK), also known as stress-activated protein kinase (SAPK), is involved in signaling events downstream of RAFTK/Pyk2 activation (35). The JNK kinases have also been shown to participate in cellular proliferation via transcriptional activation (36-38). Since OSM previously has been shown to activate JNK in KS cells (39), we studied the activation of JNK by VEGF and VRP in KS to better characterize signaling pathways from linking cytokine receptors to events involved in transcriptional activation.

\section{Methods}

Cells and cell culture. The human KS cell line KS 59 was derived from the cutaneous biopsy of an AIDS patient as previously described (10, 40-42). Similarly, a different KS cell line, KS 38, was derived from a biopsy of a cutaneous lesion from another AIDS patient. These cell lines possess many characteristics of spindle cells in primary KS lesions and are positive for von Willebrand's factor and smooth muscle antigens. The cells were grown on $1.5 \%$ gelatincoated flasks and were carried in RPMI 1640 with $15 \%$ FCS, 2 mM glutamine, $1 \mathrm{mM}$ MEM sodium pyruvate, $0.05 \mathrm{mM}$ MEM non-essential amino acids, $1 \times$ MEM amino acids, $1 \%$ Nutridoma-HU (Boehringer Mannheim Biochemicals, Indianapolis, IN) and $50 \mu \mathrm{g} / \mathrm{ml}$ penicillin and $50 \mu \mathrm{g} / \mathrm{ml}$ streptomycin. Cultures were carried until near confluence prior to the different treatments in the signaling studies described below. 293T cells (human transformed primary embryonal kidney 293 T cells) were transfected with the FLT-4 gene and used as controls for the detection of the receptor protein as described (33). CMK megakaryocytic cells were used as a positive control for RAFTK expression (29) and Jurkat T-cells as a negative control for FLT-4 expression (30).

Reagents and antibodies. RAFTK antibodies were generated using glutathione $S$-transferase (GST)-fusion proteins to the various domains of the molecule and by immunizing New Zealand rabbits as previously described $(26,29)$. Using an ELISA assay, sera were screened for specific binding to RAFTK. Serum R-4250 was chosen for further studies based on its titer in the ELISA. Serum R-4250 did not cross-react with FAK and was specific for RAFTK. Antibodies to the VEGF receptor FLK-1, the FLT-4 receptor, paxillin, JNK as well as the recombinant GST-c-Jun $\mathrm{NH}_{2}$-protein (1-79 amino acids) were obtained from Santa Cruz Biotechnology (Santa Cruz, CA). Monoclonal anti-phosphotyrosine antibody (4G10) was obtained from Upstate Biotechnology, Inc. (Lake Placid, NY). Electrophoresis reagents were obtained from Bio-Rad Laboratories (Hercules, CA). Phorbol 12-myristate 13-acetate (PMA), the protease inhibitors leupeptin, aprotinin, and alpha 1 antitrypsin, and all other reagents were obtained from Sigma Chemical Co. (St. Louis, MO). The recombinant cytokines bFGF, TNF- $\alpha$, and IL-6 were obtained from R\&D Systems, Inc. (Minneapolis, MN). Recombinant VRP, the ligand for the FLT-4 receptor, was expressed and purified from a glioblastoma cell line as previously reported (33). Recombinant VEGF was obtained from Genentech, Inc. (South San Francisco, CA). Recombinant OSM was obtained from the AIDS Reagent Bank (Bethesda, MD).

Indirect immunofluorescence. KS 38 or KS 59 cells were cultured in Chamber Slides (Lab-tek, Naperville, IL) to $90 \%$ confluency, and were then washed twice with ice-cold PBS and fixed for $30 \mathrm{~min}$ in $4 \%$ paraformaldehyde. Cells were next washed three times with ice-cold PBS and blocked for nonspecific staining using 10\% FCS in PBS for $30 \mathrm{~min}$ on ice. FLT-4 and FLK-1 expression were determined using purified antiserum at a 1:100 dilution for $1 \mathrm{~h}$ on ice. Normal rabbit serum (NRS) was used as a control for nonspecific staining. After washing cells three times with PBS, cells were stained with secondary anti- body conjugated to FITC (Boehringer Mannheim Biochemicals) at a 1:500 dilution for $1 \mathrm{~h}$ on ice. Proteins were visualized and photographed after washing three times with PBS using an inverted fluorescence microscope.

Stimulation of cells. KS 38 or KS 59 cells, grown to $80 \%$ confluence, were serum-starved for 16-18 $\mathrm{h}$ and washed twice with HBSS (GIBCO BRL, Gaithersburg, MD) prior to PMA or cytokine treatments. KS cells were first treated with PMA to assess the effects of this chemical stimulus known to phosphorylate RAFTK in other cell systems (26-29). After a time course of stimulation with PMA was established, the effects of the various cytokines were studied. We treated cells with $100 \mathrm{ng} / \mathrm{ml}$ of VEGF, VRP, or bFGF adding $10 \mathrm{IU} /$ $\mathrm{ml}$ of heparin in each case. Treatment with $100 \mathrm{ng} / \mathrm{ml}$ of TNF- $\alpha$, OSM, or IL-6 was done in the absence of heparin. Cytokines were added to cultures singly for different time periods in vitro. Controls included media with or without $10 \mathrm{IU} / \mathrm{ml}$ heparin in the absence of cytokines. After stimulation, cell lysates were directly prepared within the culture dish by lysis in $500 \mu l$ modified RIPA buffer (50 $\mathrm{mM}$ Tris- $\mathrm{HCl}, \mathrm{pH} 7.4,1 \% \mathrm{NP}-40,0.25 \%$ sodium deoxycholate, 150 $\mathrm{mM} \mathrm{NaCl}, 1 \mathrm{mM}$ PMSF, $10 \mu \mathrm{g} / \mathrm{ml}$ of aprotinin, leupeptin and pepstatin, $10 \mathrm{mM}$ sodium vanadate, $10 \mathrm{mM}$ sodium fluoride and $10 \mathrm{mM}$ sodium pyrophosphate) per dish at varying timepoints. Total cell lysates (TCL) were clarified by centrifugation at $10,000 \mathrm{~g}$ for $10 \mathrm{~min}$. Protein concentrations were determined by protein assay (Bio-Rad Laboratories).

Immunoprecipitation and Western blot analysis. For the immunoprecipitation studies, identical amounts of protein from each sample were clarified by incubation with protein A-sepharose CL-4B (Pharmacia LKB Biotechnology, Inc., Piscataway, NJ) for $1 \mathrm{~h}$ at $4^{\circ} \mathrm{C}$. Following the removal of the protein A-sepharose by brief centrifugation, the solution was incubated with different primary antibodies as detailed below for each experiment for $4 \mathrm{~h}$ or overnight at $4^{\circ} \mathrm{C}$. The immunoprecipitations of the antibody-antigen complexes were performed by incubation for $2 \mathrm{~h}$ at $4^{\circ} \mathrm{C}$ with $75 \mu \mathrm{l}$ of the protein A-sepharose (10\% suspension). Nonspecific bound proteins were removed by washing the sepharose beads three times with the modified RIPA buffer and one time with PBS. Bound proteins were solubilized in 40 $\mu l$ of $2 \times$ Laemmli buffer and further analyzed by immunoblotting. Samples were separated on $7.5 \%$ SDS-PAGE and then transferred to nitrocellulose membranes. The membranes were blocked with $5 \%$ nonfat milk protein and probed with primary antibody for $2 \mathrm{~h}$ at RT or $4^{\circ} \mathrm{C}$ overnight. Immunoreactive bands were visualized using HRPconjugated secondary antibody and the enhanced chemiluminescent (ECL) system (Amersham Corp., Arlington Heights, IL).

In vitro GST-fusion protein RAFTK C-terminal association assay. The GST-fusion protein of the RAFTK COOH-terminal domain (amino acids 681-1,009) was amplified by the PCR technique and cloned into the pGEX-2T expression vector (Pharmacia LKB Biotechnology, Inc.) as previously described (29). The GST-fusion protein was produced by $1 \mathrm{mM}$ isopropyl $\beta$-thiogalactopyranoside induction and purified by affinity chromatography on a glutathionesepharose column according to the manufacturer's recommendations (Pharmacia LKB Biotechnology, Inc.).

For the in vitro association experiments, TCL $(1 \mathrm{mg})$ of the stimulated KS cells were mixed with $5 \mu \mathrm{g}$ of the purified GST-fusion protein of the RAFTK C-terminal domain (29) and incubated for $1 \mathrm{~h}$ at $4^{\circ} \mathrm{C}$ on a rotatory shaker. $50 \mu \mathrm{l}$ of the glutathione-sepharose $4 \mathrm{~B}$ beads (Pharmacia LKB Biotechnology, Inc.) were added to preabsorb the complex. After incubation for $3 \mathrm{~h}$ at $4^{\circ} \mathrm{C}$ on a rotatory shaker, the beads were centrifuged and washed three times with the modified RIPA buffer. The bound proteins were eluted by boiling in Laemmli sample buffer and subjected to SDS-PAGE on a $7.5 \%$ gel and to Western blot analysis.

JNK kinase assay. Cell lysates were immunoprecipitated with JNK antibody (Santa Cruz Biotechnology). The immune complexes were washed twice with RIPA buffer and once in kinase buffer (50 $\mathrm{mM}$ Hepes, $\mathrm{pH} 7.4,10 \mathrm{mM} \mathrm{MgCl} 2,100 \mu \mathrm{M}$ ATP). The complex was then incubated in kinase buffer containing recombinant GST c-Jun 
$0.2 \mu \mathrm{g} / \mu \mathrm{l}$ (1-79 amino acids) (Santa Cruz Biotechnology) and $5 \mu \mathrm{Ci}$ $\left[\gamma^{32} \mathrm{P}\right] \mathrm{ATP}$ for $30 \mathrm{~min}$ at RT. The reaction was terminated by adding $2 \times$ SDS sample buffer and boiling the sample for $5 \mathrm{~min}$ at $100^{\circ} \mathrm{C}$. Proteins were separated on $12 \%$ SDS-PAGE and detected by autoradiography. Rabbit IgG was used as a negative control.

In vitro kinase assay. Cell lysates were immunoprecipitated with RAFTK antiserum. The immunoprecipitated complexes were washed twice with RIPA buffer and once in kinase buffer $(20 \mathrm{mM}$ Hepes, $\mathrm{pH} 7.4,50 \mathrm{mM} \mathrm{NaCl}, 5 \mathrm{mM} \mathrm{MgCl}, 5 \mathrm{mM} \mathrm{MnCl}_{2}$, and $100 \mathrm{mM}$ $\mathrm{Na}_{3} \mathrm{VO}_{4}$ ). The immune complex was incubated in kinase buffer containing $25 \mu \mathrm{g}$ of poly (Glu/Tyr) $(4: 1,20-50 \mathrm{kD}$; Sigma Chemical Co.) and $5 \mu \mathrm{Ci}\left[\gamma^{32} \mathrm{P}\right] \mathrm{ATP}$ at $\mathrm{RT}$ for $30 \mathrm{~min}$. The reaction was stopped by adding $2 \times$ SDS sample buffer and boiling the sample for $5 \mathrm{~min}$ at $100^{\circ} \mathrm{C}$. Proteins were then separated on $7.5 \%$ SDS-PAGE and detected by autoradiography. Normal rabbit serum was used as a negative control.

\section{Results}

Kaposi's Sarcoma cells express FLK-1 and FLT-4 receptors. To characterize the effects of different cytokines on KS cell signaling, we first examined the KS 38 and KS 59 cell lines for the expression of receptors for members of the VEGF family. Because KS spindle cells appear to be derived from the lymphatic endothelium, we focused on the recently identified FLT-4 receptor as well as on the VEGF receptor FLK-1 (30$34,43)$. Using indirect immunofluorescence, the expression of both the FLK-1 receptor and the FLT- 4 receptor was readily observed (data not shown). The presence of the FLT-4 recep-

A.

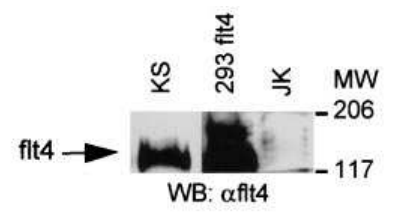

B-I.

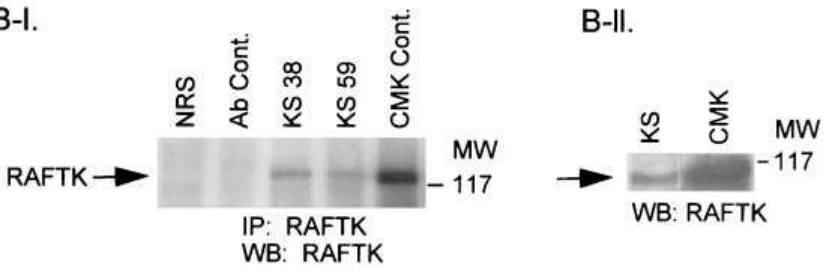

Figure 1. (A) Expression of FLT-4 in KS 38 cells. TCL from KS 38 cells were resolved on $7.5 \%$ SDS-PAGE, transferred onto a nitrocellulose membrane and immunoblotted with the anti-FLT-4 antibody. TCL from human embryonic kidney $293 \mathrm{~T}$ cells transfected with FLT-4 were used as a positive control and Jurkat (JK) T cells were used as a negative control. $(B)$ Expression of RAFTK in KS 38 and KS 59 cells detected by immunoprecipitation or Western blot analysis. TCL ( $1 \mathrm{mg}$ ) from KS 38 or KS 59 cells were immunoprecipitated with the anti-RAFTK antibody, using the same amount of cell lysate from CMK megakaryocytic cells as a positive control. Immunoprecipitates or TCL were size-fractionated on 7.5\% SDS-PAGE, transferred onto a nitrocellulose membrane and then immunoblotted with anti-RAFTK antibody. NRS and antibody alone were used as negative controls $(B-I)$. TCL $(100 \mathrm{mg})$ from KS 38 cells were size-fractionated on $7.5 \%$ SDS-PAGE, transferred onto a nitrocellulose membrane and then immunoblotted with anti-RAFTK antibody. The same amount of total cell lysate from the CMK megakaryocytic cells was used as a positive control for RAFTK $(B-I I)$.
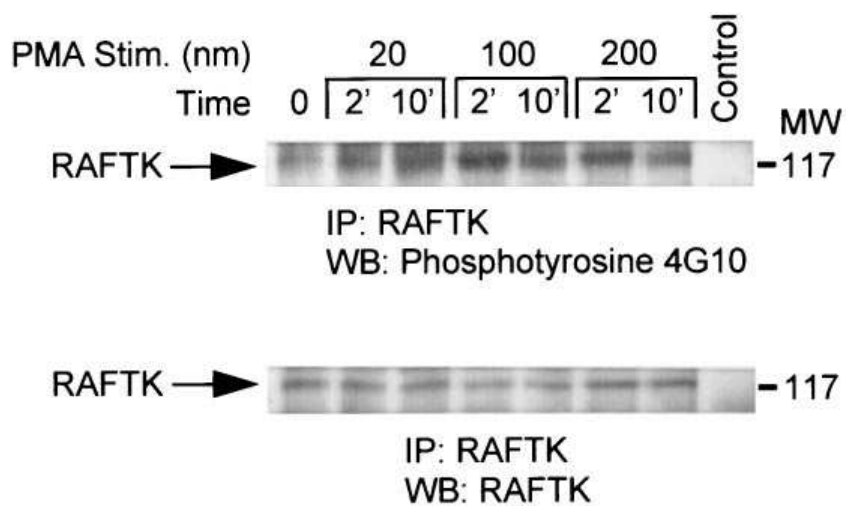

Figure 2. Tyrosine phosphorylation of RAFTK in KS 38 cells by PMA stimulation. Starved KS 38 cells were treated with the indicated concentration of PMA for 2 or 10 min. TCL from treated or untreated cells were immunoprecipitated with the anti-RAFTK antibody. Immunoprecipitates were size-fractionated on $7.5 \%$ SDS-PAGE, and subjected to serial immunoblotting with anti-phosphotyrosine antibody (top) and anti-RAFTK antibody (bottom). Antibody alone was used as a negative control.

tor was confirmed by Western blot analysis using a specific FLT-4 polyclonal antibody (Fig. $1 A$ ).

RAFTK is expressed in Kaposi's Sarcoma cells and phosphorylated upon cytokine treatment. We proceeded to further characterize the KS cells for the expression of RAFTK, a molecule that appears to be activated in brain and hematopoietic cells and reported previously to link surface signals to the JNK signaling pathway $(26-29,35)$. As shown in Fig. 1, $B-I$ and $B-I I, \mathrm{KS} 38$ or KS 59 cells expressed significant amounts of RAFTK protein as detected by Western blotting and immunoprecipitation.

Treatment of KS 38 cells with the chemical inducer PMA resulted in a time-dependent phosphorylation of RAFTK (Fig. 2). Similar results were observed with KS 59 cells (data not shown), so that all subsequent experiments were performed in KS 38 cells. Having established that RAFTK is expressed and can be phosphorylated in KS 38 cells, we studied whether the treatment of these cells with VEGF or VRP, respective ligands for the FLK-1 and FLT-4 receptors, would result in the activation of RAFTK signaling pathways. As shown in Fig. $3 A$, there was a clear time-dependent phosphorylation of RAFTK in response to VRP. Similar changes were observed following treatment with VEGF. We noted some fluctuation in the phosphorylation of RAFTK over this time course of treatment, which may represent the activity of endogenous phosphatases.

Previously, cytokines such as bFGF, OSM, IL-6, and TNF- $\alpha$ have been reported to promote the in vitro proliferation of KS cells. Thus, we analyzed the effects of treatment with these cytokines on RAFTK phosphorylation in KS 38 cells. As shown in Fig. 3, $B-D$, each of these cytokines resulted in the phosphorylation of this novel tyrosine kinase. In each of these studies, we observed changes in RAFTK phosphorylation without alteration of RAFTK protein levels (see bottom panels, Fig. 3, $A-D$ ). As seen in other studies (29), RAFTK was detected as a single or double band depending on the resolution of the gels.

Cytokine treatment of Kaposi's Sarcoma cells enhances RAFTK association with the cytoskeletal protein paxillin. Following our observation that RAFTK was phosphorylated by 
A.
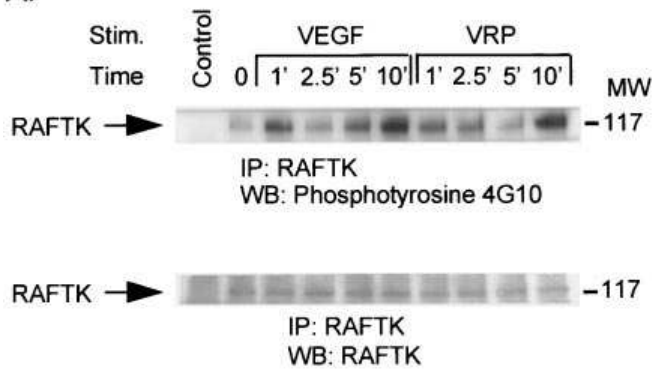

C.
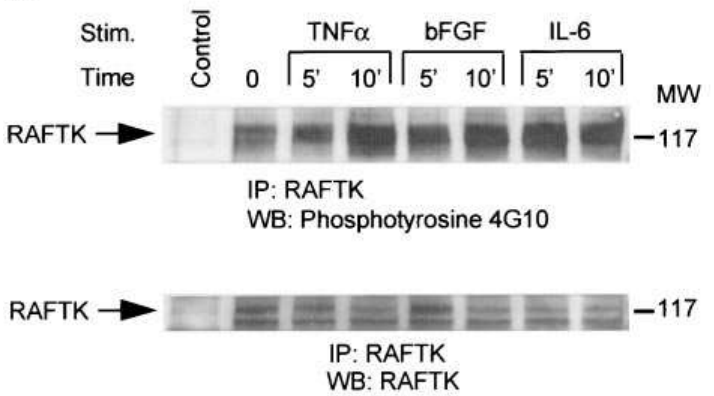

B.
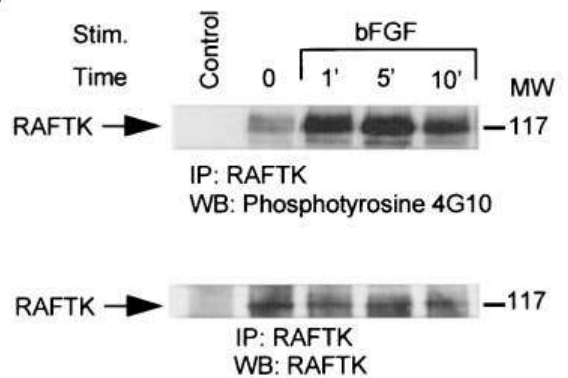

D.
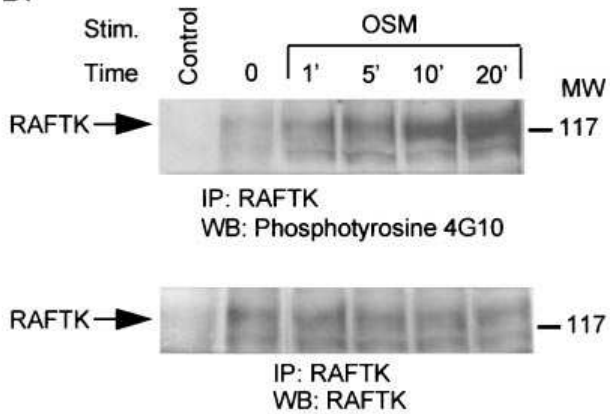

Figure 3. Tyrosine phosphorylation of RAFTK in KS 38 cells by cytokine treatment. KS 38 cells were serum-starved overnight and then treated with VEGF $(100 \mathrm{ng} / \mathrm{ml}+$ $10 \mathrm{IU} / \mathrm{ml}$ heparin) or VRP $(100 \mathrm{ng} / \mathrm{ml}+10$ IU/ml heparin) $(A)$; bFGF (100 ng/ml + 10 $\mathrm{IU} / \mathrm{ml}$ heparin) alone (B); TNF- $\alpha(100 \mathrm{ng} / \mathrm{ml})$ or IL-6 $(100 \mathrm{ng} / \mathrm{ml})$ with bFGF as a positive control $(C)$; and OSM $(100 \mathrm{ng} / \mathrm{ml})(D)$ for the indicated time period. TCL $(1 \mathrm{mg})$ from treated or untreated cells were immunoprecipitated with the anti-RAFTK antibody. Immunoprecipitates were resolved on $7.5 \%$ SDS-PAGE and subjected to serial immunoblotting with the antiphosphotyrosine antibody (top) and anti-RAFTK antibody (bottom). NRS was used as a negative control. the cytokines OSM, IL-6, bFGF, and TNF- $\alpha$ which are known to stimulate KS cell growth, as well as the endothelial growth factors VEGF and VRP which modulate cell permeability (43) and migration (33-34), we asked if this phosphorylation might

A.

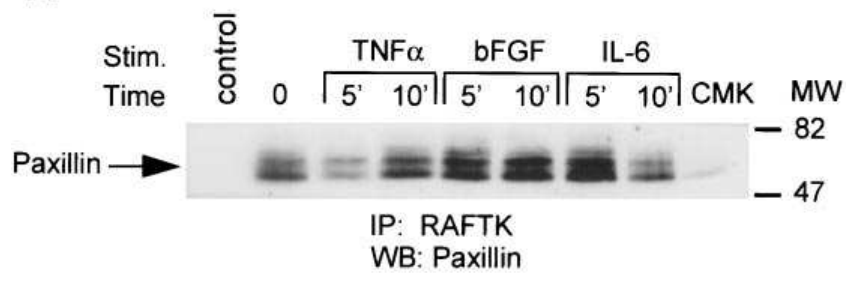

B.

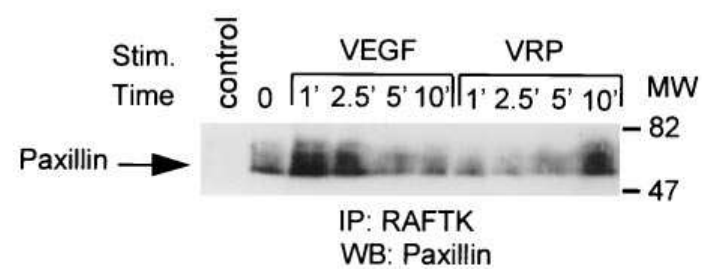

Figure 4. Association of RAFTK with paxillin in cytokine treated KS 38 cells. Cell lysates from KS 38 cells treated with TNF- $\alpha$, bFGF or IL-6 $(A)$, or VEGF or VRP $(B)$ were immunoprecipitated by the anti-RAFTK antibody. The immunoprecipitates were resolved on $7.5 \%$ SDS-PAGE, transferred onto a nitrocellulose membrane and immunoblotted with the anti-paxillin antibody. NRS was used as a negative control. modulate the association of RAFTK with certain cytoskeletal molecules. Previously, we have seen colocalization of RAFTK with vinculin in human megakaryocytes by confocal microscopy (29). Using RAFTK immunoprecipitation followed by immunoblotting with antipaxillin antibodies, we found an association of these two molecules which increased following cytokine treatments at different time points (Fig. 4, $A$ and $B$ ).

There was no uniform kinetics to this association following the different cytokine treatments. To further characterize this association, we immunoprecipitated with the $\mathrm{COOH}$-terminal domain of RAFTK and immunoblotted with antipaxillin antibodies. As shown in Fig. 5, paxillin associated with the $\mathrm{COOH}$

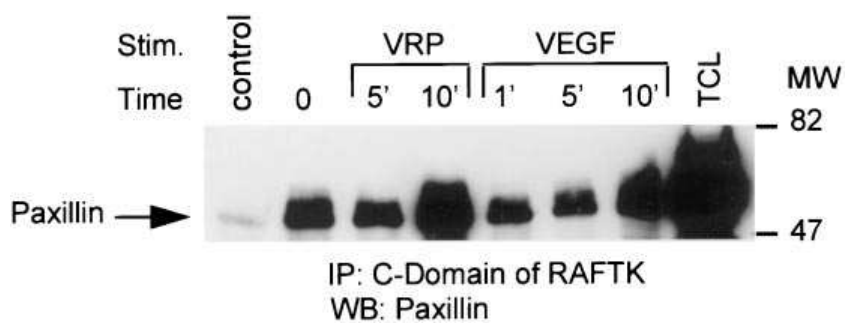

Figure 5. Association of the GST-fusion protein RAFTK COOH-terminal domain with paxillin. Unstimulated or stimulated KS 38 cell lysates were immunoprecipitated with the GST-fusion protein RAFTK C-terminal domain, separated on 7.5\% SDS-PAGE, transferred onto a nitrocellulose membrane and immunoblotted with the anti-paxillin antibody. TCL with Glutathione Sepharose beads were used as a negative control. 


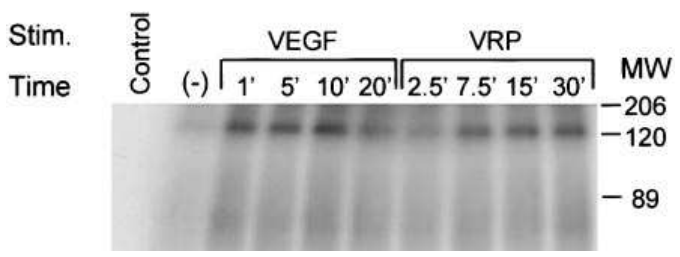

Figure 6. Stimulation of in vitro tyrosine kinase activity of RAFTK following VEGF or VRP treatment. Unstimulated or stimulated KS cell lysates were immunoprecipitated with RAFTK antibody. The immune complex was incubated with kinase buffer containing $25 \mu \mathrm{g}$ of poly (Glu/Tyr) (4:1) and $5 \mu \mathrm{Ci}\left[\gamma^{32} \mathrm{P}\right] \mathrm{ATP}$ at RT for $30 \mathrm{~min}$. The ${ }^{32} \mathrm{P}-$ incorporated proteins were resolved on $7.5 \%$ SDS-PAGE followed by autoradiography.

terminus of RAFTK. This association increased following VRP or VEGF stimulation.

Cytokine stimulation activates the protein tyrosine kinase activity of RAFTK. The tyrosine phosphorylation of protein tyrosine kinases can result in the activation of its kinase activity, which is essential for its role in signal transduction. We therefore performed an in vitro kinase assay in which poly (Glu/Tyr) (4:1) was used as an exogenous substrate to determine the intrinsic tyrosine kinase activity of RAFTK. As shown in Fig. 6, VEGF or VRP stimulation of KS cells resulted in the activation of the intrinsic tyrosine kinase activity of RAFTK. However, the kinetics of this kinase activation were different from those of the total tyrosine phosphorylation of RAFTK. This difference may be a result of the use of an exogenous substrate.

Activation of JNK activity by OSM, VEGF, and VRP. JNK is a novel member of the mitogen-activated protein kinase (MAPK) family, and has recently been shown to be a downstream mediator of the RAFTK/Pyk2 signaling pathway.

A.

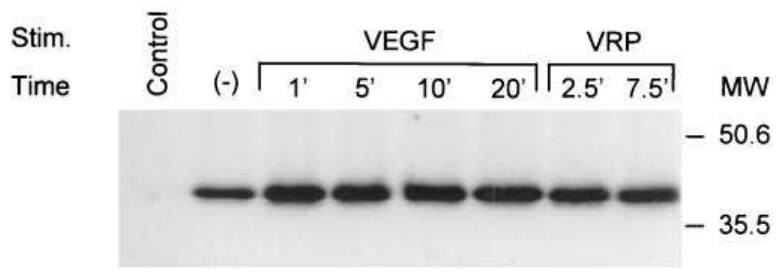

B.

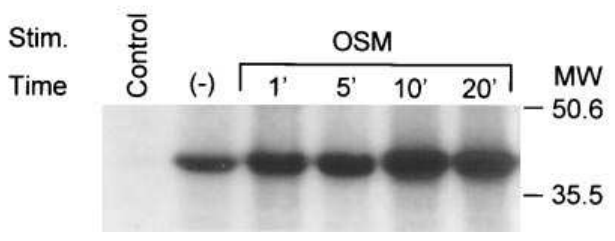

Figure 7. VEGF and VRP activate the JNK kinase in KS 38 cells. Unstimulated or stimulated KS 38 cell lysates were immunoprecipitated with the anti-JNK antibody. The immune complex was incubated with kinase buffer containing $5 \mu \mathrm{Ci}\left[\gamma^{32} \mathrm{P}\right]$ ATP and $0.2 \mu \mathrm{g} / \mu \mathrm{l}$ GST-c-Jun at RT for $30 \mathrm{~min}$. The reaction products were resolved on $12 \%$ SDS-PAGE and detected by autoradiography.
Previously, OSM and bFGF have been reported to increase JNK activity in KS cells (39). We therefore sought to determine if other cytokines which we observed to stimulate RAFTK phosphorylation and activity also activated JNK in KS cells. As shown in Fig. $7 A$, VEGF and VRP stimulation of $\mathrm{KS}$ cells resulted in the activation of JNK as determined by the phosphorylation of GST-c-Jun (1-79 amino acids). Earlier studies using GST-c-Jun immunoprecipitates showed that OSM treatment increased JNK activity in KS cells (39). In this study, we also found an increase in JNK activity in anti-JNK immunoprecipitates upon OSM treatment (Fig. 7 B).

\section{Discussion}

The development of authentic permanent KS cell lines has afforded the opportunity to characterize the surface structures of these cells and to examine which cytokines may modulate their proliferation. There is extensive literature supporting a role for a number of cytokines in modulating $\mathrm{KS}$ cell growth via autocrine or paracrine mechanisms (8-20). The characterization of signaling pathways in KS cells and the effects of these cytokines on such pathways have been less extensively explored. Amaral et al. (44) found that OSM activated the MAP kinase pathway, while Faris et al. (39) reported that members of the Jak/Stat family of kinases known to participate in signaling via the gp130 receptor were active in KS cells as well. In our studies, we chose the KS 38 cell line derived from a patient with cutaneous KS as a model because of its previously characterized properties that closely correspond to those of primary pathological KS specimens $(40,41)$. However, there are limitations within in vitro cell models, particularly the lack of infection of KSHV. We sought to identify on these KS cells novel receptors which are preferentially expressed in normal lymphatic endothelium, and to further characterize the signaling pathways that may link surface receptor activation to the cytoskeleton and transcriptional activation in these cells.

The tyrosine kinase FLT-4 receptor is relatively restricted in expression in normal tissues, with prior studies indicating its presence on the surface of the lymphatic endothelium as well as microvascular endothelial cells (30-32). We observed that KS 38 cells, whose characteristics resemble those of spindle cells in primary lesions, express FLT-4 as well as the related FLK-1 receptor. We also observed that VRP, the ligand for the FLT-4 receptor, as well as VEGF, the ligand for FLK-1, induced significant signaling changes in KS 38 cells based on the enhanced phosphorylation of their proteins. After this observation, we sought to identify whether or not there are shared signaling molecules whose enhanced phosphorylation is a common response to these cytokines as well as those cytokines previously reported to stimulate KS cells.

We were aware that a variety of ligands and receptors from different molecular families have been implicated in the pathogenesis of KS. To survey this range of cytokines, we chose representative cytokines from each family and performed a comparative analysis of bFGF, TNF- $\alpha$, OSM, and IL- 6 with VEGF and VRP. We found that in all these diverse cytokine signaling pathways, the recently identified RAFTK molecule was phosphorylated and its kinase activity enhanced.

RAFTK appears to function as a platform kinase upon which a number of intracytoplasmic kinases and adapter molecules converge. The convergence of such molecules likely facilitates the transmission of surface signals to the cytoskeleton. 
Previous studies from several laboratories including our own indicate a role for RAFTK/Pyk2 in calcium-mediated signaling in brain as well as signaling by integrins and certain cytokines such as the stem cell factor/kit ligand in megakaryocytes (2629). Recently, RAFTK/Pyk2 was shown to couple with the JNK signaling pathway in PC12 neuronal and 293T kidney cells upon its activation by stress signals (35). JNK activation is a pivotal step in the regulation of certain transcriptional mediators such as AP-1 (45).

In this study, we report that after RAFTK activation by these diverse cytokines there was enhanced association of this kinase with the cytoskeletal protein paxillin. Previously, in megakaryocytes, RAFTK was seen to colocalize with vinculin, another cytoskeletal protein (29). In KS 38 cells, the association of the kinase with paxillin appeared to be mediated by the proline-rich COOH-terminal domain of RAFTK. This interaction may contribute to cytokine modulation of KS cell migration and/or adhesion, as is suggested by the recent report of RAFTK's association with paxillin in hematopoietic cells (46). The $\mathrm{COOH}$ terminus of the related focal adhesion kinase FAK is similarly hydrophobic and mediates many signaling and cytoskeletal interactions $(47,48)$. Also of note is the finding of JNK kinase activation by VEGF or VRP in KS cells. Activation of JNK by OSM has been previously reported (39).

The finding that such a diverse group of cytokines is able to phosphorylate a single intracellular molecule which appears to link surface signals to the cytoskeleton and to pathways of transcriptional activation may help to explain the apparent redundancy of the growth promoting effects on KS cells of each of these specific cytokines. Further studies on the role of RAFTK in KS cells will aim to specifically inhibit its kinase function and evaluate the effects on downstream signaling pathways such as JNK.

\section{Acknowledgments}

We are very thankful to Dr. James Lee and Dr. William I. Wood from Genentech, Inc. for providing VRP and VEGF. We are also thankful to Dr. Hava Avraham for her helpful discussion and for providing RAFTK antibody. We are grateful to Janet Delahanty for her editing and for the preparation of the figures for this manuscript, and Jennifer McGrath for her assistance with the figures. We would also like to thank Eun-Young Kim and Malvika Tickoo for their assistance with tissue culture. Finally, we appreciate Youngsun Jung and Tee Trac for their typing assistance and Delroy Heath for facilitating our receipt of the needed reagents for the experiments.

This work was supported in part by National Institutes of Health grants HL-53745-02, HL-43510-07, HL-55187-01, HL-51456-02, and HL-55445-01. Dr. Hatch is supported by a David Geffen fellowship.

This manuscript is submitted in honor of Ronald Ansin for his friendship and support for our research program.

\section{References}

1. Dictor, M. 1988. Vascular remodeling in Kaposi's sarcoma and avian hemangiomatosis: relation to the vertebrate lymphatic system. Lymphology. 21: 53-60.

2. Dorfman, R.F. 1988. Kaposi's sarcoma: evidence supporting its origin from the lymphatic system. Lymphology. 21:45-52.

3. Chang, Y., E. Cesarman, M.S. Pessin, F. Lee, J. Culpepper, D.M. Knowles, and P.S. Moore. 1994. Identification of herpesvirus-like DNA sequences in AIDS-associated Kaposi's sarcoma [see comments]. Science (Wash. DC). 266:1865-1869.

4. Zhong, W., H. Wang, H.B. Herndier, and D. Ganem. 1996. Restricted expression of Kaposi's sarcoma-associated herpesvirus (human herpesvirus 8) genes in Kaposi's sarcoma. Proc. Natl. Acad. Sci. USA. 93:6641-6646.
5. Huang, Y.Q., J.J. Li, W.G. Zhang, D. Feiner, and A.E. Friedman-Kien. 1996. Transcription of human herpesvirus-like agent (HHV-8) in Kaposi's sarcoma. J. Clin. Invest. 97:2803-2806.

6. Humphrey, R.W., T.R. O’Brien, F.M. Newcomb, H. Nishihara, K.M. Wyvill, G.A. Ramos, M.W. Saville, J.J. Goedert, S.E. Straus, and R. Yarchoan. 1996. Kaposi's sarcoma (KS)-associated herpesvirus-like DNA sequences in peripheral blood mononuclear cells: association with KS and persistence in patients receiving anti-herpesvirus drugs. Blood. 88:297-301.

7. Ensoli, B., G. Barillari, S.Z. Salahuddin, R.C. Gallo, and F. Wong-Staal. 1990. Tat protein of HIV-1 stimulates growth of cells derived from Kaposi's sarcoma lesions of AIDS patients. Nature (Lond.). 345:84-86.

8. Barillari, G., L. Buonaguro, V. Fiorelli, J. Hoffman, F. Michaels, R.C. Gallo, and B. Ensoli. 1992. Effects of cytokines from activated immune cells on vascular cell growth and HIV-1 gene expression. Implications for AIDSKaposi's sarcoma pathogenesis. J. Immunol. 149:3727-3734.

9. Buonaguro, L., G. Barillari, H.K. Chang, C.A. Bohan, V. Kao, R. Morgan, R.C. Gallo, and B. Ensoli. 1992. Effects of the human immunodeficiency virus type 1 Tat protein on the expression of inflammatory cytokines. J. Virol. 66:7159-7167.

10. Cai, J., P.S. Gill, R. Masood, P. Chandrasoma, B. Jung, R.E. Law, and S.F. Radka. 1994. Oncostatin-M is an autocrine growth factor in Kaposi's sarcoma. Am. J. Pathol. 145:74-79.

11. Ensoli, B., G. Barillari, and R.C. Gallo. 1992. Cytokines and growth factors in the pathogenesis of AIDS-associated Kaposi's sarcoma. Immunol. Rev. 127:147-155.

12. Ensoli, B., S. Nakamura, S.Z. Salahuddin, P. Biberfeld, L. Larsson, B. Beaver, F. Wong-Staal, and R.C. Gallo. 1989. AIDS-Kaposi's sarcoma-derived cells express cytokines with autocrine and paracrine growth effects. Science (Wash. DC). 243:223-226.

13. Fiorelli, V., R. Gendelman, F. Samaniego, P.D. Markham, and B. Ensoli. 1995. Cytokines from activated $\mathrm{T}$ cells induce normal endothelial cells to acquire the phenotypic and functional features of AIDS-Kaposi's sarcoma spindle cells. J. Clin. Invest. 95:1723-1734.

14. Huang, Y.Q., J.J. Li, K.S. Kim, A. Nicolaides, W.G. Zhang, J. Le, B.J. Poiesz, and A.E. Friedman-Kien. 1993. HIV-1 infection and modulation of cytokine and growth factor expression in Kaposi's sarcoma-derived cells in vitro. AIDS (Phila.). 7:317-322

15. Ganem, D. 1995. AIDS. Viruses, cytokines and Kaposi's sarcoma. Curr. Biol. 5:469-471.

16. Miles, S.A. 1994. Pathogenesis of HIV-related Kaposi's sarcoma. Curr. Opin. Oncol. 6:497-502.

17. Ensoli, B., R. Gendelman, P. Markham, V. Fiorelli, S. Colombini, M. Raffeld, A. Cafaro, H.K. Chang, J.N. Brady, and R.C. Gallo. 1994. Synergy between basic fibroblast growth factor and HIV-1 Tat protein in induction of Kaposi's sarcoma. Nature (Lond.). 371:674-680.

18. Miles, S.A., A.R. Rezai, J.F. Salazar-Gonzalez, M. Vander Meyden, R.H. Stevens, D.M. Logan, R.T. Mitsuyasu, T. Taga, T. Hirano, T. Kishimoto, and O. Martinez-Maza. 1990. AIDS Kaposi sarcoma-derived cells produce and respond to interleukin 6. Proc. Natl. Acad. Sci. USA. 87:4068-4072.

19. Nair, B.C., A.L. DeVico, S. Nakamura, T.D. Copeland, Y. Chen, A. Patel, T. O'Neil, S. Oroszlan, R.C. Gallo, and M.G. Sarngadharan. 1992. Identification of a major growth factor for AIDS-Kaposi's sarcoma cells as oncostatin M. Science (Wash. DC). 255:1430-1432.

20. Weindel, K., D. Marme, and H.A. Weich. 1992. AIDS-associated Kaposi's sarcoma cells in culture express vascular endothelial growth factor. Biochem. Biophys. Res. Commun. 183:1167-1174.

21. Yang, J., M.K. Hagan, and M.K. Offermann. 1994. Induction of IL-6 gene expression in Kaposi's sarcoma cells. J. Immunol. 152:943-955.

22. Brown, T.J., J.M. Rowe, J.W. Liu, and M. Shoyab. 1991. Regulation of IL-6 expression by oncostatin M. J. Immunol. 147:2175-2180.

23. Buonaguro, L., F.M. Buonaguro, G. Giraldo, and B. Ensoli. 1994. The human immunodeficiency virus type 1 Tat protein transactivates tumor necrosis factor beta gene expression through a TAR-like structure. J. Virol. 68:2677-2682.

24. Maier, J.A., M. Mariotti, A. Albini, P. Comi, M. Prat, P.M. Comogilio, and M.R. Soria. 1996. Over-expression of hepatocyte growth factor in human Kaposi's sarcoma. Int. J. Cancer. 65:168-172.

25. Sciacca, F.L., M. Sturzl, F. Bussolino, M. Sironi, H. Brandstetter, C. Zietz, D. Zhou, C. Matteucci, G. Peri, S. Sozzani, et al. 1994. Expression of adhesion molecules, platelet-activating factor, and chemokines by Kaposi's sarcoma cells. J. Immunol. 153:4816-4825.

26. Avraham, S., R. London, Y. Fu, S. Ota, D. Hiregowdara, J. Li, S. Jiang L.M. Pasztor, R.A. White, J.E. Groopman, and H. Avraham. 1995. Identification and characterization of a novel related adhesion focal tyrosine kinase (RAFTK) from megakaryocytes and brain. J. Biol. Chem. 270:27742-27751.

27. Lev, S., H. Moreno, R. Martinez, P. Canoll, E. Peles, J.M. Musacchio, G.D. Plowman, B. Rudy, and J. Schlessinger. 1995. Protein tyrosine kinase Pyk2 involved in $\mathrm{Ca}^{2+}$-induced regulation of ion channel and MAP kinase functions. Nature (Lond.). 376:737-745.

28. Sasaki, H., K. Nagura, M. Ishino, H. Tobioka, K. Kotani, and T. Sasaki. 1995. Cloning and characterization of cell adhesion kinase $\beta$, a novel proteintyrosine kinase of the focal adhesion kinase subfamily. J. Biol. Chem. 270: 21206-21219. 
29. Li, J., H. Avraham, R.A. Rogers, S. Raja, and S. Avraham. 1996. Characterization of RAFTK, a novel focal adhesion kinase, and its integrin-dependent phosphorylation and activation in megakaryocytes. Blood. 88:417-428.

30. Kaipainen, A., J. Korhonen, T. Mustonen, V.W. van Hinsbergh, G.-H. Fang, D. Dumont, M. Breitman, and K. Alitalo. 1995. Expression of the fmslike tyrosine kinase 4 gene becomes restricted to lymphatic endothelium during development. Proc. Natl. Acad. Sci. USA. 92:3566-3570.

31. Kaipainen, A., J. Korhonen, K. Pajusola, O. Aprelikova, M.G. Persico, B.I. Terman, and K. Alitalo. 1993. The related FLT4, FLT1, and KDR receptor tyrosine kinases show distinct expression patterns in human fetal endothelial cells. J. Exp. Med. 178:2077-2088.

32. Hewett, P.W., and J.C. Murray. 1996. Coexpression of flt-1, flt-4 and KDR in freshly isolated and cultured human endothelial cells. Biochem. Biophys. Res. Commun. 221:697-702.

33. Lee, J., A. Gray, J. Yuan, S-M. Luoh, H. Avraham, and W.I. Wood. 1996. Vascular endothelial growth factor-related protein: a ligand and specific activator of the tyrosine kinase receptor Flt4. Proc. Natl. Acad. Sci. USA. 93: 1988-1992.

34. Joukov, V., K. Pajusola, A. Kaipainen, D. Chilov, I. Lahtinen, E. Kukk, O. Saksela, N. Kalkkinen, and K. Alitalo. 1996. A novel vascular endothelial growth factor, VEGF-C, is a ligand for the FLT4 (VEGFR-3) and KDR (VEGFR-2) receptor tyrosine kinases. EMBO (Eur. Mol. Biol. Organ.) J. 15: 290-298.

35. Tokiwa, G., I. Dikic, S. Lev, and J. Schlessinger. 1996. Activation of Pyk2 by stress signals and coupling with JNK signaling pathway. Science (Wash. DC.). 273:792-794.

36. Derijard, B., M. Hibi, I.-H. Wu, T. Barrett, B. Su, T. Deng, M. Karin, and R.J. Davis. 1994. JNK-1: a protein-kinase stimulated by UV light and HaRas that binds and phosphorylates the c-Jun activation domain. Cell. 76:10251037.

37. Hibi, M., A. Lin, T. Smeal, A. Minden, and M. Karin. 1993. Identification of an oncoprotein- and UV-responsive protein kinase that binds and potentiates the c-Jun activation domain. Genes Dev. 7:2135-2148.

38. Kallunki, T., B. Su, I. Tsigelny, H.K. Sluss, B. Derijard, G. Moore, R. Davis, and M. Karin. 1994. JNK2 contains a specificity determining region responsible for efficient c-Jun binding and phosphorylation. Genes Dev. 8:2996-3007.
39. Faris, M., B. Ensoli, N. Stahl, G. Yancopoulis, A. Nguyen, S. Wang, and A.E. Nel. 1996. Differential activation of the extracellular signal-regulated kinase, Jun Kinase and Janus Kinase-Stat pathways by oncostatin $\mathrm{M}$ and basic fibroblast growth factor in AIDS-derived Kaposi's sarcoma cells. AIDS (Phila.). 10:369-378.

40. Masood, R., S.R. Husain, A. Rahman, and P. Gill. 1993. Potentiation of cytotoxicity of Kaposi's sarcoma related to immunodeficiency syndrome (AIDS) by liposome-encapsulated doxorubicin. AIDS Res. Hum. Retroviruses. 9:741-746.

41. Masood, R., Y. Lunardi-Iskandar, L.F. Jean, J.R. Murphy, C. Waters, R.C. Gallo, and P. Gill. 1994. Inhibition of AIDS-associated Kaposi's sarcoma cell growth by DAB389-interleukin 6. AIDS Res. Hum. Retroviruses. 10:969975

42. Guo, W., T. Antakly, M. Cadotte, Z. Kachra, L. Kunkel, R. Masood, and P.S. Gill. 1996. Expression and cytokine regulation of glucocorticoid receptors in Kaposi's sarcoma. Am. J. Pathol. 148:1999-2007.

43. Brown, L.F., K. Tognazzi, H.F. Dvorak, and T.J. Harrist. 1996. Strong expression of kinase insert domain-containing receptor, a vascular permeability factor/vascular endothelial growth factor receptor in AIDS-associated Kaposi's sarcoma and cutaneous angiosarcoma. Am. J. Pathol. 148:1065-1074.

44. Amaral, M.C., S. Miles, G. Kumar, and A.E. Nel. 1993. Oncostatin-M stimulates tyrosine protein phosphorylation in parallel with the activation of p42 MAPK/ERK-2 in Kaposi's cells. Evidence that this pathway is important in Kaposi cell growth. J. Clin. Invest. 92:848-857.

45. Angel, P., K. Hattori, T. Smeal, and M. Karin. 1988. The jun protooncogene is positively autoregulated by its product, Jun/AP-1. Cell. 55:875-885.

46. Salgia, R., S. Avraham, E. Pisick, J.-L. Li, S. Raja, E.A. Greenfield, M. Sattler, H. Avraham, and J.D. Griffin. 1996. The related adhesion focal tyrosine kinase forms a complex with paxillin in hematopoietic cells. J. Biol. Chem. 271: 31222-31226.

47. Clark, E.A., and J.S. Brugge. 1995. Integrins and signal transduction pathways. Science (Wash. DC). 268:233-239.

48. Bellis, S.L., J.T. Miller, and C.E. Turner. 1995. Characterization of tyrosine phosphorylation of paxillin in vitro by focal adhesion kinase. J. Biol. Chem. 270:17437-17441. 